\title{
Contribution of domestic production records, Interbull estimated breeding values, and single nucleotide polymorphism genetic markers to the single-step genomic evaluation of milk production
}

\author{
J. Přibyl, ${ }^{* 1}$ P. Madsen,† J. Bauer, ${ }^{*}$ J. Přibylová, ${ }^{*}$ M. Šimečková, ${ }^{*}$ L. Vostrý, ${ }^{*}$ and L. Zavadilová* \\ *Institute of Animal Science, Přátelství 815, 10401 Praha - Uhříněves, Czech Republic \\ †Department of Molecular Biology and Genetics, Aarhus University, Blichers Allé 20, Postboks 50, DK-8830 Tjele, Denmark
}

\section{ABSTRACT}

Estimated breeding values (EBV) for first-lactation milk production of Holstein cattle in the Czech Republic were calculated using a conventional animal model and by single-step prediction of the genomic enhanced breeding value. Two overlapping data sets of milk production data were evaluated: (1) calving years 1991 to 2006, with 861,429 lactations and 1,918,901 animals in the pedigree and (2) calving years 1991 to 2010, with 1,097,319 lactations and 1,906,576 animals in the pedigree. Global Interbull (Uppsala, Sweden) deregressed proofs of 114,189 bulls were used in the analyses. Reliabilities of Interbull values were equivalent to an average of 8.53 effective records, which were used in a weighted analysis. A total of 1,341 bulls were genotyped using the Illumina BovineSNP50 BeadChip V2 (Illumina Inc., San Diego, CA). Among the genotyped bulls were 332 young bulls with no daughters in the first data set but more than 50 daughters $(88.41$, on average) with performance records in the second data set. For young bulls, correlations of EBV and genomic enhanced breeding value before and after progeny testing, corresponding average expected reliabilities, and effective daughter contributions (EDC) were calculated. The reliability of prediction pedigree EBV of young bulls was 0.41 , corresponding to $\mathrm{EDC}=10.6$. Including Interbull deregressed proofs improved the reliability of prediction by $\mathrm{EDC}=13.4$ and including genotyping improved prediction reliability by $\mathrm{EDC}=6.2$. Total average expected reliability of prediction reached 0.67 , corresponding to $\mathrm{EDC}=30.2$. The combination of domestic and Interbull sources for both genotyped and nongenotyped animals is valuable for improving the accuracy of genetic prediction in small populations of dairy cattle.

Key words: genomic breeding value, single-step prediction, BLUP, genomic relationship

\footnotetext{
Received September 14, 2012.

Accepted November 12, 2012

${ }^{1}$ Corresponding author: pribyl.josef@vuzv.cz
}

\section{INTRODUCTION}

The detection of genetic loci and their association with economically important production traits of animals are of great interest to researchers (e.g., Abdolmohammadi et al., 2011; Bolečková et al., 2012). Genomic enhanced breeding value (GEBV) prediction has become a routine practice in dairy cattle breeding for assessment of genetic merit of young bulls. The majority of procedures currently used in this approach require multiple steps, wherein for genotyped sires with highly reliable EBV, pseudo-data of daughter yield deviations (DYD; Rozzi et al., 1990; Szyda et al., 2008) and their weights - effective daughter contributions (EDC) - are calculated. These DYD and EDC are subsequently used together with high-density genetic SNP markers for prediction of direct genetic value (DGV) and in combination with residual polygenic effects for prediction of GEBV (Meuwissen et al., 2001). The group of genotyped animals is usually strongly preselected, and proper comparison within an entire population requires error-free input parameters and adjustments. The GEBV of genotyped animals also retroactively influence EBV of nongenotyped animals in the given population. Methodology is in constant development, aimed at creating a single-step procedure (single-step genomic BLUP, ssGBLUP). The primary motivation for development of the single-step procedure was to account for genomic preselection, thereby avoiding the bias that results when only the above-average progeny of parents get the opportunity to have phenotypes. Calculation of GEBV by ssGBLUP uses nationwide databases of production records and pedigree files directly, in which only a portion of animals are genotyped, together with genetic markers in one conjoint evaluation of genotyped and nongenotyped animals (Misztal et al., 2009; Aguilar et al., 2010; Christensen and Lund, 2010).

Methodological approaches for GEBV calculation have been described by VanRaden et al. (2009), Prribyl et al. (2010), and Poschadel and Mayer (2011). New developments in ssGBLUP methodology involving mainly the genomic relationship matrix $(\mathbf{G})$, which is an es- 
PŘIBYL ET AL.

Table 1. Mean values and variability of input data ( $\mathrm{kg}$ of milk/lactation)

\begin{tabular}{lrrrc}
\hline Item $^{1}$ & & & & SD \\
& $\mathrm{n}$ & Mean & $\mathrm{SD}$ & (adjusted) $^{2}$ \\
\hline Lactation I & 861,429 & 6,122 & 1,884 & 1,043 \\
Lactation II & $1,097,319$ & 6,554 & 2,024 & 1,083 \\
Interbull YD III $^{3}$ & 114,189 & -157 & 795 & \\
\hline
\end{tabular}

${ }^{1}$ Set I = calving years 1991 to 2006 ; set II = calving years 1991 to 2010; set III = Interbull (Uppsala, Sweden) November 2011 deregressed EBV for milk production converted into the domestic scale comparable with phenotype. Phenotypic averages for bulls. YD = yield deviations.

${ }^{2}$ Production adjusted by LSM for systematic environmental effects.

${ }^{3}$ Average reliability of input Interbull EBV was 0.74 , corresponding to effective record contribution (ERC) of 8.53

sential part of this procedure, are described in Legarra et al. (2009), Goddard et al. (2011), and Vitezica et al. (2011). Single-step GBLUP analyses have been applied to many species, populations, and traits (Aguilar et al., 2011; Chen et al., 2011; Tsuruta et al., 2011).

In all the above-mentioned prediction methods, accuracy of genomic evaluation depends on volume of data evaluated, number of genotyped animals in a reference population, and density of genetic SNP markers (Hayes et al., 2009; VanRaden et al., 2009). Both EBV and GEBV are either direct or indirect reflections of performance records. Sources of information for GEBV calculation are either direct phenotype production records or phenotypes previously processed by animal model analyses. Therefore, databases of phenotypes (as in ssGBLUP) or pseudo-phenotypes based on previously calculated EBV (as in multi-step methods) could be used for calculation of GEBV. Reliability of EBV and, therefore, of GEBV as well, depends in all cases on a size and distribution of data in original production recording.

In dairy cattle, sources of information for genetic evaluation of animals are national databases of production records, the global Interbull (Uppsala, Sweden; www.interbull.org) database of EBV of progeny-tested bulls, or both sources. Interbull EBV are frequently used for GEBV calculations in multi-step procedures. To account for the fact that genetic correlation is not unity between a trait measured in different countries (genotype $\times$ environment interaction), Interbull EBV are transformed into national scale (Schaeffer, 1994). The objective of the present study was to combine the domestic database of production records for Holstein cattle with Interbull EBV into one joint evaluation of GEBV to improve accuracy of evaluation within a domestic population.

\section{MATERIALS AND METHODS}

\section{Data Sets}

Production records from first lactations of Czech Holstein cows and the Interbull EBV database for milk production of Holsteins were used in this study. Summary statistics for the data sets are in Table 1 . Two overlapping data sets of domestic milk production performance data and one converted data set were used:

(I) 861,429 305-d lactation records, with calving years 1991 to 2006 ;

(II) 1,097,319 305-d lactation records, with calving years 1991 to 2010 ;

(III) Interbull November 2011 EBV for milk production for 114,189 Holstein bulls converted into the domestic conditions. Interbull EBV on a national scale were modified, so the variability of EBV of domestic proven bulls and variability of Interbull EBV were similar. Estimated breeding values were deregressed (Rozzi et al., 1990; Szyda et al. 2008) and pseudo-data YD and effective record contributions (ERC) were calculated as follows:

$$
\mathrm{ERC}=\frac{1-\mathrm{h}^{2}}{\mathrm{~h}^{2}} \cdot \frac{\mathrm{rel}}{1-\mathrm{rel}}
$$

where rel $=$ reliability of EBV. In the following, the Interbull data are referred to as data set III.

\section{Methods of Evaluation}

Data were analyzed by BLUP (EBV), GBLUP (DGV), and ssGBLUP (GEBV) procedures, using the following animal model:

$$
\begin{gathered}
y_{i j}=H Y S_{i}+\beta_{1} \cdot c a_{j}+\beta_{2} \cdot c a_{j}^{2}+\beta_{3} \cdot d o_{j} \\
+\beta_{4} \cdot d o_{j}^{2}+a n_{j}+e_{i j},
\end{gathered}
$$

where $y_{i j}=$ milk performance; $H Y S_{i}=$ contemporary group within a herd in a 3 -mo calving period (fixed effect); $\beta_{1}, \beta_{2}, \beta_{3}$, and $\beta_{4}=$ regression coefficients; $c a_{j}$ and $c a_{j}^{2}=$ parameters for curvilinear regressions on calving age (fixed effect); $d o_{j}$ and $d o_{j}^{2}=$ parameters for curvilinear regressions on days open (fixed effect); $a n_{j}$ 
$=$ animal; and $e_{i j}=$ random error. The assumption of random effects was as follows:

$$
\left[\begin{array}{l}
a n \\
e
\end{array}\right] \approx N\left(\left[\begin{array}{l}
0 \\
0
\end{array}\right],\left[\begin{array}{cc}
\mathbf{Q} \sigma_{a}^{2} & 0 \\
0 & \mathbf{D} \sigma_{e}^{2}
\end{array}\right]\right),
$$

where $\sigma_{a}^{2}=$ additive genetic variance, $\sigma_{e}^{2}=$ residual variance, and $\mathbf{D}=$ diagonal matrix with reciprocal weights. Weights are 1.0 for phenotypic data and ERC for pseudo-data $\mathrm{YD}$, and $\mathbf{Q}$ is one of the following: pedigree-based relationship matrix $(\mathbf{A})$, genomic relationship matrix $(\mathbf{G})$, or pedigree relationship matrix augmented with the genomic relationship matrix $(\mathbf{H})$.

Matrix A covered up to 6 known ancestral generations. The ultimate generations of ancestors were assigned to phantom parent groups according to a combination of breeds (Holstein, Red Holstein, and Simmental), birth years $(<1980,1980-1989,1990-1999$, and $>1999)$, and country of origin (North America, Western Europe, and Czech Republic/Slovakia). The totals used were 21 groups for females and another 21 groups for males. The pedigree included 1,918,901 and 1,906,576 animals for data set I and II, respectively. The pedigree in data set I also included animals from the Interbull database.

Matrix G was calculated according to deviations from the averages of observed allele frequencies and standardized by division by the average value of the diagonal of $\mathbf{G}$, so that the average of diagonal elements $=1$ (Forni et al., 2011), and shifted, so that the elements of the additive pedigree relationship matrix only for genotyped animals $\mathbf{A}_{22}$ and elements of $\mathbf{G}$ have the same average (Vitezica et al., 2011). Matrix $\mathbf{G}$ was constructed for 1,341 genotyped bulls using genetic SNP markers from the Illumina Bovine SNP50 BeadChip V2 (Illumina Inc., San Diego, CA). Among genotyped bulls, 731 had more than 20 daughters (103.46 daugh- ters, on average) with production records in data set I, and among that group, 589 bulls had more than 50 daughters (119.65, on average) in data set I. A total of 332 young genotyped bulls did not have daughters in data set I but had more than 50 daughters (88.41, on average) with production records in data set II. The remaining genotyped bulls had a smaller number of daughters.

Matrix $\mathbf{H}$ was the pedigree additive relationship matrix A augmented by genomic relationship matrix G (Aguilar et al., 2010; Christensen and Lund, 2010). Weights of $80 \% \mathbf{G}$ and $20 \% \mathbf{A}_{22}$ were used for incorporation into $\mathbf{H}$.

Seven different strategies (A-G) for combining sources of information for genetic evaluation and evaluation methods were evaluated. The strategies are described in Table 2.

Deregressed Interbull EBV (here referred to as YD) were considered to be the same trait as the domestic phenotype trait. Yield deviations were allocated to one additional $H Y S$ class and parameters of other effects from the model equation were kept constant (average values of the independent variable). The YD represents averages for each bull; variability of each observation was handled in a weighted analysis, where the weights were ERC.

\section{Validation of Procedures}

For different strategies, the averages and variabilities of EBV and differences between young 332 genotyped bulls and reference groups of bulls proven in set I were calculated. For the 332 young genotyped bulls, correlations were calculated between EBV I, using only pedigree information and no progeny information in data set I, and EBV II, calculated after progeny testing. The correlation between GEBV I and EBV II was also

Table 2. Strategies evaluated including combination of input data [domestic and Interbull (Uppsala, Sweden)] and methods of evaluation

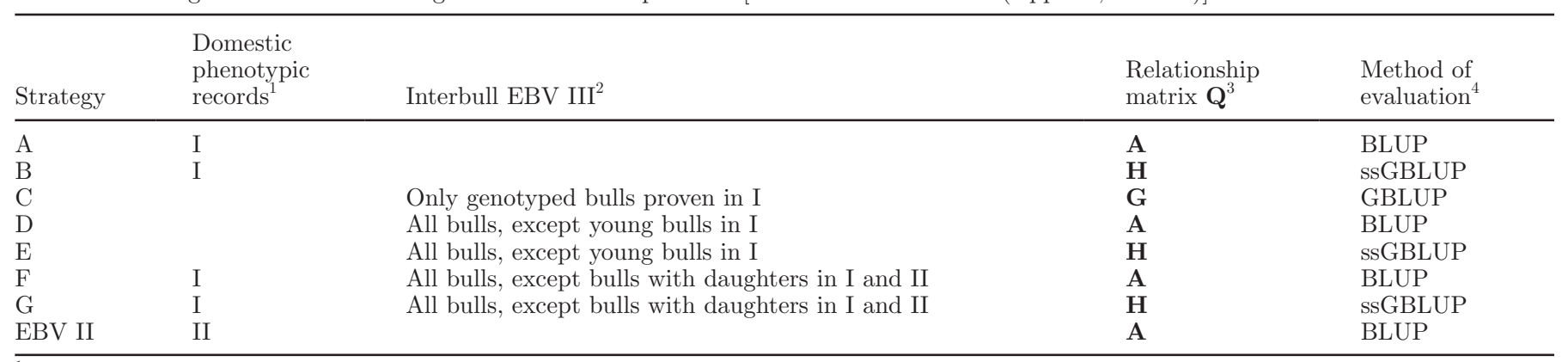

${ }^{1} \mathrm{I}=$ data set I (calving years 1991 to 2006 ); II = data set II (calving years 1991 to 2010).

${ }^{2} \mathrm{III}=$ Interbull deregressed EBV.

${ }^{3} \mathbf{A}=$ pedigree relationship matrix $\mathbf{G}=$ genomic relationship matrix; $\mathbf{H}=$ combined relationship matrix.

${ }^{4}$ ssGBLUP $=$ single-step genomic BLUP. 
calculated. This is approximately equal to the genetic correlation $\left(\mathrm{r}_{\mathrm{G}}\right)$ multiplied by the square roots of the reliabilities:

$$
\mathrm{r}_{\mathrm{I} \times \mathrm{II}}=(\mathrm{rel} \mathrm{I})^{1 / 2} \mathrm{r}_{\mathrm{G}}(\mathrm{rel} \mathrm{II})^{1 / 2} .
$$

The approximate reliability after progeny testing in set II is as follows:

$$
\text { rel II }=\frac{\mathrm{EDC}}{\mathrm{EDC}+\frac{1-0.25 \mathrm{~h}^{2}}{0.25 \mathrm{~h}^{2}}},
$$

where EDC is the sum according to contribution of progeny and contribution of pedigree.

We worked with the genetic value for the same trait of the same animals. Therefore, we assumed the genetic correlation before and after progeny test to be 1 , and approximation of average reliability of EBV in data set I follows from back calculation of the previous formulas:

$$
\text { rel I }=\mathrm{r}_{\mathrm{I} \times \mathrm{II}}^{2} /(\text { rel II }) .
$$

From the reliability, it is possible to calculate EDC as follows:

$$
\mathrm{EDC}=\frac{1-0.25 \mathrm{~h}^{2}}{0.25 \mathrm{~h}^{2}} \cdot \frac{\mathrm{rel}}{1-\mathrm{rel}} .
$$

For 332 young genotyped bulls, the EBV after progeny test II were regressed on predictions in set I and the mean square errors (MSE) of prediction from regression analysis were calculated.

A heritability of 0.25 was used for all calculations. The BLUPF90 family of programs (Misztal et al., 2002) and the DMU5 module of the DMU software (Madsen and Jensen, 2010) were used for the EBV and GEBV predictions. The $\mathbf{G}$ was built using the G-matrix programs (Su and Madsen, 2011). Databases and descriptive statistics were handled in SAS (SAS Institute Inc., Cary, NC).

\section{RESULTS}

\section{Input Data}

Average milk production in the population increased over the years and, therefore, had a higher average and variability in data set II than in data set I (Table 1). After adjustment for systematic environmental effects according to the model described above, the phenotypic standard deviations were slightly above $1,000 \mathrm{~kg}$ of milk. Pseudo-data YD III had already been corrected for systematic environmental effects and had a lower standard deviation $(795 \mathrm{~kg})$ than the phenotypic standard deviation of milk records because YD were, on average, based on 8.53 observations (ERC).

\section{Relationship}

Relationship statistics among genotyped animals are summarized in Table 3. The inbreeding coefficients (diagonal elements are sums of 1 and inbreeding coefficients) of $\mathbf{A}_{22}$ and $\mathbf{G}$ differed, on average, by only 0.044 , but variability was higher for G. Differences of inbreeding (diagonal elements) between matrices had similar variability to that of genomic inbreeding (0.042). The maximal negative change between corresponding elements of matrix $\mathbf{A}_{\mathbf{2 2}}$ and matrix $\mathbf{G}$ was -0.218 and maximal positive change 0.099. Off-diagonal elements (relationships) had the same averages and variabilities for both matrices. Maximum negative and positive changes of relationships (off-diagonal elements) between corresponding elements of matrix $\mathbf{A}_{22}$ and matrix $\mathbf{G}$ were -0.471 and 0.524 . The correlation between inbreeding values between matrices was 0.23 , and the correlation among relationship values between matrices was 0.69. These values are lower than reported for 838 bulls of the same population by Prribyl et al. (2012): 0.31 and 0.74 , respectively.

\section{Prediction of EBV and GEBV}

Prediction of genetic values was by regular animal model for strategies A, D, and F; by ssGBLUP for strategies B, E, and G; and by the multi-step procedure (C), equivalent to the GBLUP method using the $\mathbf{G}$ matrix (VanRaden, 2008). Summary statistics of calculated EBV are summarized in Table 4. Averages and variabilities of GEBV and EBV were similar for strategies $\mathrm{A}, \mathrm{B}, \mathrm{F}$, and $\mathrm{G}$, which used domestic data (data set I). Across strategies, GEBV of the group of young bulls generally had slightly higher variabilities than EBV calculated from the same data sets. These higher variabilities were associated with higher reliabilities.

\section{Strategies $A$ and $B$}

Regular EBV in data set I were calculated for $1,918,901$ animals. In this group, 731 genotyped and proven bulls had 76,629 daughters, an average of 103.46 per sire. The SD of EBV in the entire population was $708 \mathrm{~kg}$. In data set I, 2,552 bulls were already proven with $>50$ daughters (126.89, on average). The average EBV of these proven bulls was $633 \mathrm{~kg}$ above the population mean, with a standard deviation of $737 \mathrm{~kg}$ (slightly higher than the standard deviation of entire population). 
Table 3. Pedigree $\left(\mathbf{A}_{22}\right)$ and genomic $(\mathbf{G})$ relationship matrices for 1,341 genotyped bulls

\begin{tabular}{|c|c|c|c|c|c|}
\hline Item & Mean & SD & Minimum & Maximum & $\begin{array}{c}\text { Correlation } \\
\mathbf{A}_{22} \times \mathbf{G}\end{array}$ \\
\hline \multicolumn{6}{|c|}{ Diagonal elements $(1+$ inbreeding $)$} \\
\hline $\mathbf{A}_{22}$ & 1.038 & 0.023 & 1.000 & 1.172 & \\
\hline G & 1.082 & 0.040 & 0.959 & 1.296 & \\
\hline Difference $\mathbf{A}_{22}-\mathbf{G}$ & -0.044 & 0.042 & -0.218 & 0.099 & 0.23 \\
\hline \multicolumn{6}{|c|}{ Off-diagonal elements (relationship) } \\
\hline $\mathbf{A}_{22}$ & 0.081 & 0.046 & 0 & 0.688 & \\
\hline G & 0.081 & 0.045 & -0.060 & 0.690 & \\
\hline Difference $\mathbf{A}_{22}-\mathbf{G}$ & 0 & 0.036 & -0.471 & 0.524 & 0.69 \\
\hline
\end{tabular}

The average pedigree EBV of the 332 young genotyped bulls was 1,439 $\mathrm{kg}$ above the population mean, which represents a difference of approximately +2 standard deviations. The variability of EBV of this selected group $(471 \mathrm{~kg})$ was lower than in the entire population and lower than that of proven bulls. This has ramifications with respect to reliabilities, as will be discussed below. The average EBV of young genotyped bulls was higher by $806 \mathrm{~kg}$ than the average of the referenced group of proven bulls.

The GEBV in data set I were almost identical to the traditional EBV with respect to averages and variability described in the previous paragraph, except for slightly higher variability of GEBV among the young genotyped bulls. The superiority of young genotyped bulls to those from the reference group of proven bulls was similar for traditional EBV and GEBV.

\section{Strategy C}

From the Interbull database (III), 748 bulls were chosen that were genotyped and had already been progeny tested in the domestic Czech population (I).
The average reliability of their Interbull EBV was 0.96, which corresponds to an ERC of 82.32. Therefore, the reference population for evaluation was represented by $748 \times 82.32=61,575$ weights. Information in the subsequent analysis corresponds to a database of EDC $=307,875$ daughters of genotyped bulls. In total, only 1,341 genotyped animals were evaluated. A residual polygenic effect was not included in the model; therefore, calculated values are DGV. The average DGV of the 332 young bulls was $106 \mathrm{~kg}$ above the average of all genotyped animals, and the standard deviation was 278 $\mathrm{kg}$. This variability is much lower than in evaluations of EBV and GEBV in the entire domestic population (strategies A and B). Only Interbull EBV were used and, therefore, the evaluation was not dependent on the domestic population.

\section{Strategies $D$ and $E$}

All available bulls from the Interbull database (set III) were used for evaluation. The source of information was 114,189 pseudo-daughter YD, equivalent to an average ERC of 8.53 per sire. This represents 114,189 $\times$

Table 4. Means and variability of EBV and genomic enhanced breeding value (GEBV) for milk production (kg) per lactation

\begin{tabular}{|c|c|c|c|c|c|c|c|}
\hline \multirow{2}{*}{$\begin{array}{l}\text { Calculated value, } \\
\text { evaluated data, } \\
\text { and strategy }{ }^{1}\end{array}$} & \multicolumn{2}{|c|}{ All data ${ }^{2}$} & \multicolumn{2}{|c|}{ Proven bulls ${ }^{3}$} & \multicolumn{3}{|c|}{332 young genotyped bulls } \\
\hline & $\mathrm{n}$ & $\mathrm{SD}$ & Mean & $\mathrm{SD}$ & Mean & $\mathrm{SD}$ & Difference $^{4}$ \\
\hline $\mathrm{EBV}, \mathrm{I}, \mathrm{A}$ & $1,918,901$ & 708 & 633 & 737 & 1,439 & 471 & 806 \\
\hline GEBV, I, B & $1,918,901$ & 708 & 632 & 736 & 1,434 & 487 & 802 \\
\hline DGV, III, C C $^{5}$ & 1,341 & 414 & & & 107 & 278 & \\
\hline EBV, III, D & 303,563 & 888 & & & 1,409 & 476 & \\
\hline GEBV, III, E & 303,563 & 887 & & & 1,379 & 490 & \\
\hline $\mathrm{EBV}, \mathrm{I}+\mathrm{III}, \mathrm{F}$ & $1,918,901$ & 697 & 635 & 702 & 1,336 & 513 & 701 \\
\hline GEBV, I+III, G & $1,918,901$ & 697 & 634 & 702 & 1,323 & 528 & 689 \\
\hline $\mathrm{EBV}, \mathrm{II}$ & $1,906,576$ & 737 & 625 & 747 & 1,455 & 599 & 830 \\
\hline
\end{tabular}


$8.51=971,748$ weights available for evaluation, which also correspond to $\mathrm{EDC}=4,858,740$ daughters. Evaluated animals were 1,341 genotyped animals and animals from database III and ancestors up to the sixth generation (a total of 303,563 animals). Variability of EBV for the whole population $(\mathrm{SD}=888 \mathrm{~kg}$ ) was higher than in the domestic population $(\mathrm{SD}=708)$. This could be caused by higher precision of input data (deregressed proofs) compared with only phenotypes in set I. The average EBV for the 332 young genotyped bulls was slightly lower but variability was similar to evaluations of only the domestic population (set I), strategies A and B. The GEBV had similar averages and variabilities as traditional EBV.

\section{Strategies $F$ and $G$}

For strategies $\mathrm{F}$ and $\mathrm{G}$, all data available from domestic production recording (set I) and the Interbull database (set III) were used, and weighted analyses were performed. In total, 1,918,901 animals were evaluated. Variabilities of EBV in the entire population were similar to those in strategies $\mathrm{A}$ and $\mathrm{B}$, and the differences in averages and variabilities of EBV of the group of proven bulls were similar to those in the domestic population. However, the group of 332 young genotyped bulls differed from the entire population and from the reference group of proven bulls by $105 \mathrm{~kg}$ less in strategy $\mathrm{F}$ compared with strategy A, and by 113 $\mathrm{kg}$ less in strategy G compared with strategy B. The differences from the group of proven bulls was $701 \mathrm{~kg}$ in strategy $\mathrm{F}$ and $689 \mathrm{~kg}$ in strategy $\mathrm{G}$, even though the difference of proven bulls from the population mean remained the same as in strategies A and B. Variability among breeding values of young bulls was slightly higher than as estimated in other strategies. This may be related to higher reliabilities of evaluation of young animals, as discussed below.

\section{$E B V$ II}

When the entire domestic population through calving year 2010 was evaluated (data set II), variabilities of EBV of all animals, and especially of the 332 young genotyped bulls who had no progeny records in set I, were higher than in data set I ( $\mathrm{SD}=599$ vs. 471, respectively). This in accordance with the higher reliability of evaluation (see below), but could also partly be caused by a scale effect, because progeny of young genotyped bulls came into production in later years, with higher production and higher variability (Table 1). The difference in average EBV from the reference group of proven bulls was $830 \mathrm{~kg}$, slightly higher than in evaluation of young animals in set I. This indicates good agreement between results in both data sets and that over-valuation of young animals resulting from pedigree EBV or GEBV calculated in an older database (set I) was not manifested.

\section{Correlations Between Evaluations}

Correlations of EBV and GEBV of the 332 young genotyped bulls with their results after progeny testing and expected average reliabilities are summarized in Table 5. In data set II, after progeny testing, these 332 bulls had an average of 88.41 daughters with records. Within herds, for each tested daughter, there were approximately 4 unrelated, tested contemporaries, resulting in the effective number of daughters being approximately $80 \%$ of the actual number. Pedigree information was equivalent to about 10.6 of progeny (EDC; see below). Therefore, for approximation of average reliability of EBV (set II), we used $\mathrm{EDC}=88.41 \cdot 0.80$ $+10.6=81.3$, which corresponds to average reliability (Table 5):

$$
\text { rel II }=\mathrm{EDC} /\left[\mathrm{EDC}+\left(1-0.25 \cdot \mathrm{h}^{2}\right) / 0.25 \cdot \mathrm{h}^{2}\right]=0.84 .
$$

The correlation between pedigree EBV of the 332 young genotyped bulls in data set I, strategy A, with their EBV after progeny test in data set II equaled 0.59 .

Pedigree EBV (strategy A), following from this calculation, had an approximate reliability of 0.41 , corresponding to an effective daughter contribution as follows:

$$
\mathrm{EDC}=\left[\left(1-0.25 \cdot \mathrm{h}^{2}\right) / 0.25 \cdot \mathrm{h}^{2}\right][\mathrm{rel} /(1-\mathrm{rel})]=10.6
$$

The mean square error of regression of EBV II on EBV I was 485.6.

The GEBV of young genotyped bulls depends on information of daughters of both genotyped and nongenotyped bulls and other relatives. The GEBV in strategy B had higher correlation to the post-progeny test estimates (0.67), which corresponded to rel $\mathrm{I}=$ $0.53, \mathrm{EDC}=17.1$, and a lower MSE of 448.8. The increase in correlation from strategy $\mathrm{A}$ is equivalent to an additional $17.1-10.6=6.5$ daughters.

Strategy C, working only with the relatively small number of genotyped bulls and their YD, yielded a correlation of 0.63 , average reliability (rel I) of 0.47 , and EDC of 13.4. The reliability of prediction was higher than from using only pedigree information in strategy A, but lower than from GEBV in strategy B, in which information contributed by nongenotyped animals was also used to evaluate young candidates. 
Table 5. Correlations for 332 young genotyped bulls between EBV and genomic enhanced breeding value (GEBV) in data set I with EBV in data set II, expected average reliability, and corresponding effective daughter contributions (EDC) and mean square errors (MSE)

\begin{tabular}{lcccc}
$\begin{array}{l}\text { Calculated value, } \\
\text { evaluated data, } \\
\text { and strategy }^{1}\end{array}$ & Correlation & Reliability & EDC & MSE $^{2}$ \\
\hline EBV I, A & 0.59 & 0.41 & 10.6 & 485.6 \\
GEBV, I, B & 0.67 & 0.53 & 17.1 & 448.8 \\
DGV, III, C & 0.63 & 0.47 & 13.4 & 464.9 \\
EBV, III, D & 0.69 & 0.57 & 19.5 & 431.8 \\
GEBV, III, E & 0.73 & 0.63 & 25.9 & 414.1 \\
EBV, I+III, F & 0.72 & 0.62 & 24.0 & 419.2 \\
GEBV, I+III, G & 0.75 & 0.67 & 30.2 & 396.8 \\
EBV, II & & 0.84 & 81.3 & \\
Difference & 0.03 & 0.05 & & \\
Genotyping G - F & 0.13 & 0.21 & 13.4 & -22.4 \\
Size of data F - A & 0.16 & 0.26 & 19.6 & -86.4 \\
Total G - A & & & & \\
\hline
\end{tabular}

${ }^{1} \mathrm{I}=$ data set I (calving years 1991 to 2006 ); II = data set II (calving years 1991 to 2010); III = Interbull deregressed EBV.

${ }^{2}$ Mean square error of regression of EBV II on prediction by EBV I or GEBV I.

${ }^{3}$ Direct genetic value (DGV) III C = limited deregressed proofs for 748 genotyped bulls.

Using all Interbull information (set III) and strategy $\mathrm{D}$, the correlations were as follows: $\mathrm{EBV}=0.69$, rel I $=0.57$, and $\mathrm{EDC}=19.5$. This increase from previous strategies may also be caused by the fact that young bulls used in the Czech population are mainly of foreign origin. Therefore, they have a closer connection to the global Interbull database than to the domestic population. In addition, the Interbull database has massive information content.

For strategy E, the correlation among GEBV was 0.73 , a higher value than if only domestic data were used as in strategy B and much higher than if only YD of genotyped bulls were used as in strategy C. Using the combination of domestic and Interbull databases as in strategy $\mathrm{F}$ achieved a correlation for EBV of 0.72 , rel I of 0.62 , and EDC of 24. Corresponding values for GEBV strategy G were correlation of 0.75 , rel I of 0.67 , and EDC of 30.2.

The total change in reliability of prediction of EBV of young bulls in the domestic population strategy (A) from rel $\mathrm{I}=0.41$ to the GEBV in combined data sets (strategy G) rel $\mathrm{I}=0.67$ was equivalent to an increase in EDC of 19.6 daughters. This increase in reliability can be apportioned between 2 causes: the increase in information from the Interbull database $(\mathrm{EDC}=13.4)$ and the use of genotypic information $(\mathrm{EDC}=6.2)$.

\section{DISCUSSION}

Criteria used to compare different breeding value prediction strategies in population I included correlation between EBV and GEBV estimates and EBV II estimates (the highest reliability "control"), reliability,
EDC, and MSE. The most appropriate way to assess the accuracy of a prediction method is to relate the prediction to subsequent performance rather than subsequent evaluation that includes parent information, which increases the similarity. Using such a measure is unlikely to change the conclusions from this study. Important are differences between compared strategies; all of them were affected by the same methodology of validation. Regardless of the criteria used, the ranking of all of the strategies tested was the same.

Correlations between strategies and their EBV (set II) observed in present study were higher than in a previous study on the same population (Prribyl et al., 2012), which were 0.50 for EBV (set I) and 0.54 for GEBV (set I), when a smaller population was used that included approximately one-third as many genotyped and proven bulls as used here.

In the present study, strategy $\mathrm{C}$ is a widely used multi-step GBLUP procedure using only YD of genotyped bulls. This strategy had higher average reliabilities than if only pedigree information had been used as in strategy A, but lower reliability than single-step GEBV in strategy B, working with the entire domestic population, and strategy $\mathrm{E}$ in which all YD were used. All information from both genotyped and nongenotyped animals contributed to the reliability of young bulls in strategies B and E, as also stated in Gao et al. (2012) and Su et al. (2012).

Strategies F and G, which used both domestic and Interbull databases, achieved the highest accuracies of prediction (Table 5) and, thus, more accurate ranking of a group of young bulls. However, these strategies had smaller differences in average predicted values 
of young bulls compared with the reference group of proven bulls than if only the domestic database had been used (strategies A and B; Table 4). A possible explanation is that most of the young tested bulls are progeny of foreign parents and, therefore, have closer linkages to the global Interbull database than to the domestic population. Interbull correlations between the Czech population and other countries are generally 0.85 (Interbull, 2012). Interbull values are regressed for each country following Interbull procedures. The regression coefficient for the Czech population is equivalent to the previously mentioned correlation of 0.85 . This regression resulted in decreases from original values, but it can be seen only in the joint evaluation of domestic and Interbull data sets.

Suitable methods should be developed for correction of the bias of evaluation for young bulls in strategies $\mathrm{F}$ and $\mathrm{G}$. In strategies $\mathrm{D}$ and $\mathrm{E}$, using only the Interbull data set, regression to the Czech conditions was not applied. Therefore, the difference of average EBV of young bulls from the population mean remained a higher value than in results from the combined data set.

The value of genotyping is usually expressed in terms of final accuracy. But this is, in any case, due to a combination of genotyping with volume of production records information underlying the genotyped animals. In this work, we split sources of information into 2 causal parts.

Reliability of EBV depends generally in a curvilinear manner on the amount of information upon which the EBV are based. Contribution of genotyping depends on a level of reliability already reached before genotyping. In our case, when only a limited number of animals were genotyped, the increments in reliability caused by genotyping in the same data sets were 0.41 for strategy A to 0.53 for strategy B, 0.47 for strategy D to 0.57 for strategy E, and 0.62 for strategy $\mathrm{F}$ to 0.67 for strategy $\mathrm{G}$, resulting in increments in EDC ranging from 6.2 to 6.5 daughters. The increase in correlation due to pure genotyping of 0.03 (strategy $\mathrm{G}$ and $\mathrm{F}$ ), when the level of reliability was higher, up to 0.08 (strategy $\mathrm{B}$ and A), when the level of reliability was lower, seems to be small, particularly when compared with the increase due to amount of data. This value depends on the number of genotyped bulls. In our case, the predictor population was only 731 genotyped proven bulls. The total improvement in reliability reached in our study is equivalent to $\mathrm{EDC}=19.6$ (24.5 actual daughters).

\section{CONCLUSIONS}

The increase in reliability resulting from use of genotyping is a function of the amount of phenotypic information in the reference population directly, or indirectly connected with genotyped animals. In all practical cases, the increments of accuracy of prediction are combinations of phenotypic information and genotyping. In the present study, the use of genotypic information caused an increment in EDC of 6.2 daughters, whereas using additional information caused an increment of 13.4 daughters. Reliability of GEBV estimates for young animals can be considerably enhanced by including information from genotyped and nongenotyped animals effectively combined by single-step analytical procedures. The combination of all animals from a domestic population and the global Interbull EBV database improves the prediction of both EBV and GEBV, especially in small populations. If all data are used in the traditional evaluation, and the genomic evaluation also exploits all the relevant traditional data and procedures, the single-step procedure should not cause a big increment in accuracy.

\section{ACKNOWLEDGMENTS}

We thank V. Čermák, Z. Růžička, J. Šplíchal, and M. Verner from Czech Moravian Breeding Corporation (Prague, Czech Republic) and J. Motyčka and L. Vondrášek from the Holstein Cattle Breeders Association of the Czech Republic (Prague, Czech Republic) for preparation of data files. Thanks to W. D. Hohenboken (Philomath, OR) for editing the paper and for valuable comments. We are grateful to I. Misztal (University of Georgia, Athens) for methodological support, valuable comments, and for provision of computer programs. We gratefully acknowledge the helpful comments of anonymous reviewers. Supported by the Ministry of Agriculture of the Czech Republic (Prague; projects no. MZe 0002701404 and QI111A167).

\section{REFERENCES}

Abdolmohammadi, A., H. Atashi, P. Zamani, and C. Bottema. 2011. High resolution melting as an alternative method to genotype diacylglycerol O-acyltransferase 1 (DGAT1) K232A polymorphism in cattle. Czech J. Anim. Sci. 56:370-376.

Aguilar, I., I. Misztal, D. L. Johnson, A. Legarra, S. Tsuruta, and T. J. Lawlor. 2010. Hot topic: A unified approach to utilize phenotypic, full pedigree, and genomic information for genetic evaluation of Holstein final score. J. Dairy Sci. 93:743-752.

Aguilar, I., I. Misztal, S. Tsuruta, G. R. Wiggans, and T. J. Lawlor. 2011. Multiple trait genomic evaluation of conception rate in Holsteins. J. Dairy Sci. 94:2621-2624.

Bolečková, J., J. Matejíčková, M. Štípková, J. Kyselová, and L. Bartoň. 2012. The association of five polymorphisms with milk production traits in Czech Fleckvieh cattle. Czech J. Anim. Sci. 57:45-53.

Chen, C. Y., I. Misztal, I. Aguilar, S. Tsuruta, T. H. E. Meuwissen, S. E. Aggrey, T. Wing, and W. M. Muir. 2011. Genome-wide markerassisted selection combining all pedigree phenotypic information with genotypic data in one step: An example using broiler chickens. J. Anim. Sci. 89:23-28. 
Christensen, O. F., and M. S. Lund. 2010. Genomic prediction when some animals are not genotyped. Genet. Sel. Evol. 42:2.

Forni, S., I. Aguilar, and I. Misztal. 2011. Different genomic relationship matrices for single-step analysis using phenotypic, pedigree and genomic information. Genet. Sel. Evol. 43:1 http://dx.doi. org/10.1186/1297-9686-43-1.

Gao, H., O. F. Christensen, P. Madsen, U. S. Nielsen, Y. Zhang, M. S. Lund, and G. Su. 2012. Comparison on genomic predictions using three GBLUP methods and two single-step blending methods in the Nordic Holstein population. Genet. Sel. Evol. 44:8. http:// dx.doi.org/10.1186/1297-9686-44-8.

Goddard, M. E., B. J. Hayes, and T. H. E. Meuwissen. 2011. Using the genomic relationship matrix to predict the accuracy of genomic selection. J. Anim. Breed. Genet. 128:409-421.

Hayes, B. J., P. J. Bowman, A. J. Chamberlain, and M. E. Goddard. 2009. Invited review: Genomic selection in dairy cattle: Progress and challenges. J. Dairy Sci. 92:433-443.

Interbull. 2012. International Bull Evaluation Service official website. Accessed Mar. 15, 2012. http://www.interbull.org.

Legarra, A., I. Aguilar, and I. Misztal. 2009. A relationship matrix including full pedigree and genomic information. J. Dairy Sci. 92:4656-4663.

Madsen, P., and J. Jensen. 2010. DMU - A package for analysing multivariate mixed models. Version 6, release 5.0. http://dmu.agrsci. dk/dmuv6_guide.5.0.pdf.

Meuwissen, T. H. E., B. J. Hayes, and M. E. Goddard. 2001. Prediction of total genetic value using genome-wide dense marker maps. Genetics 157:1819-1829.

Misztal, I., A. Legarra, and I. Aguilar. 2009. Computing procedures for genetic evaluation including phenotypic, full pedigree, and genomic information. J. Dairy Sci. 92:4648-4655.

Misztal, I., S. Tsuruta, T. Strabel, B. Auvray, T. Druet, and D. H. Lee. 2002. BLUPF90 and related programs (BGF90). Commun. No. 28-07 in Proc. 7th World Congr. Genet. Appl. Livest. Prod. (WCGALP), Montpellier, France.

Poschadel, N., and M. Mayer. 2011. Realisierte Verwandtschaftsmatrizen und Zuchtwerschätzung für die genomische Selektion-Eine Übersicht. Züchtungskunde 83:167-181.
Přibyl, J., J. Haman, T. Kott, J. Přibylová, M. Šimečková, L. Vostrý, L. Zavadilová, V. Čermák, Z. Růžička, J. Šplíchal, M. Verner, J. Motyčka, and L. Vondrášek. 2012. Single-step prediction of genomic breeding value in a small dairy cattle population with strong import of foreign genes. Czech J. Anim. Sci. 57:151-159.

Přibyl, J., V. Řehout, J. Čítek, and J. Přibylová. 2010. Genetic evaluation of dairy cattle using a simple heritable genetic ground. J. Sci. Food Agric. 90:1765-1773.

Rozzi, P., L. R. Schaeffer, E. B. Burnside, and W. Schlote. 1990. International evaluation of Holstein-Friesian dairy sires from three countries. Livest. Prod. Sci. 24:15-28.

Schaeffer, L. R. 1994. Multiple-country comparison of dairy sire. J. Dairy Sci. 77:2671-2678.

Su, G., and P. Madsen. 2011 User's Guide for Gmatrix. A program for computing Genomic relationship matrix. http://dmu.agrsci.dk/ Gmatrix_User_Guide.pdf.

Su, G., P. Madsen, U. S. Nielsen, E. A. Mäntysaari, G. P. Aamand, O. F. Christensen, and M. S. Lund. 2012. Genomic prediction for Nordic Red Cattle using one-step and selection index blending. J. Dairy Sci. 95:909-917.

Szyda, J., E. Ptak, J. Komisarek, and A. Żarnecki. 2008. Practical application of daughter yield deviations in dairy cattle breeding. J. Appl. Genet. 49:183-191.

Tsuruta, S., I. Misztal, I. Aguilar, and T. J. Lawlor. 2011. Multipletrait genetic evaluation of linear type traits using genomic and phenotypic data in US Holsteins. J. Dairy Sci. 94:4198-4204.

VanRaden, P. M. 2008. Efficient methods to compute genomic predictions. J. Dairy Sci. 91:4414-4423.

VanRaden, P. M., C. P. Van Tassell, G. R. Wiggans, T. S. Sonstegard, R. D. Schnabel, J. F. Taylor, and F. S. Schenkel. 2009. Invited review: Reliability of genomic predictions for North American Holstein bulls. J. Dairy Sci. 92:16-24.

Vitezica, Z. G., I. Aguilar, I. Misztal, and A. Legarra. 2011. Bias in genomic predictions for populations under selection. Genet. Res. (Camb.) 93:357-366. 